\title{
Entrevista com tarefa na identificação de processos na aprendizagem autorregulada
}

\author{
Janete Silva \\ Faculdade de Psicologia - Universidade de Lisboa - Lisboa - Portugal \\ Ana Margarida Veiga Simão \\ Faculdade de Psicologia - Universidade de Lisboa - Lisboa - Portugal
}

\begin{abstract}
Resumo
A entrevista com tarefa tem-se revelado um instrumento útil para os profissionais da educação pois, através das interações dos intervenientes, podemos avaliar os processos e as estratégias aplicados pelos aprendizes numa determinada tarefa. O modelo que seguimos é atribuído a Zimmerman (2000, 2013), com uma perspectiva sociocognitiva. Assim, pretendemos, não só averiguar se a entrevista com tarefa pode auxiliar os profissionais a identificar processos autorregulatórios na aprendizagem, como potenciá-los nos aprendizes. Efetuamos seis entrevistas semiestruturadas a dois alunos, ao realizarem um resumo. Os resultados permitem inferir sobre o planejamento estratégico que eles fazem, quais as suas crenças de autoeficácia, a capacidade de automonitorar a tarefa e aplicar estratégias de compreensão. Verificamos também a evolução nos perfis de aprendizagem já que os alunos passaram a: adequar os objetivos das estratégias, interiorizar normas de ação e fazer revisão. Dada a sua pertinência, pretendemos alargar a investigação para lhe conferir maior aplicabilidade e estender o seu potencial.
\end{abstract}

Palavras-chave: entrevista; aprendizagem; autorregulação.

\section{Interviewing with task in self-regulatory learning processes identification}

\begin{abstract}
Task Development Interviews have shown their usefulness in identifying and gathering information regarding psychological processes and strategies as students perform tasks. In light of Zimmerman's $(2000,2013)$ social-cognitive approach to self-regulated learning, this study proposes to answer two questions, namely, how Task Development Interviews can help professionals identify students' self-regulatory processes and how the latter can they prompted. Three semi-structured interviews were applied to two students performing a text summary. The findings revealed that students planned the task strategically, developed strong self-efficacy beliefs, and were able to self-monitor the task and apply comprehension strategies. Furthermore, these findings showed some development in regards to students' performance, namely through the adjustment of the task's objectives, the adoption and adaptation of norms of action and lastly, through the revision of strategy use. Due to its pertinent nature, the study will continue to be developed in order to extend the applicability and potential of the instruments used.
\end{abstract}

Keywords: interview; learning; self-regulation.

\section{Entrevista con tarea en la identificación de procesos en el aprendizaje autorregulada}

\begin{abstract}
Resumen
La entrevista con tarea se ha revelado un instrumento útil para los profesionales de la educación pues, por intermedio de las interacciones de los intervinientes, se puede evaluar los procesos y las estrategias aplicados por los aprendices en una determinada tarea. El modelo que se siguió es atribuido a Zimmerman $(2000,2013)$, con una perspectiva socio cognitiva. Así, se pretende, no sólo averiguar si la entrevista con tarea puede auxiliar los profesionales a identificar procesos auto regulatorios en el aprendizaje, sino también potenciarlos en los aprendices. Se efectuó seis entrevistas semiestructuradas a dos alumnos, al realizar un resumen. Los resultados permiten inferir sobre el planeamiento estratégico que ellos hacen, cuáles son sus creencias de autoeficacia, la capacidad de auto supervisarla tarea y aplicar estrategias de comprensión. Se verificó también la evolución en los perfiles de aprendizaje ya que los alumnos pasaron a: adecuar los objetivos de las estrategias, interiorizar normas de acción y hacer revisión. Dada a su pertinencia, se pretende alargar la investigación para conferirle mayor aplicabilidad y extender su potencial. Palabras clave: entrevista; aprendizaje; auto regulación.
\end{abstract}




\section{Introdução}

\section{Autorregulação da Aprendizagem: definição e aplicabilidade}

Verificamos hoje um considerável aumento de estudos sobre a aprendizagem regulada pelo próprio aprendiz, que resulta da interação de conhecimentos, competências e motivações necessárias ao planejamento, à organização, ao controle e à avaliação dos processos adotados e dos resultados atingidos (Lopes da Silva, Sá, Duarte, \& Veiga Simão, 2004). A lógica do processo de autorregulação da aprendizagem é o de conduzir a uma aprendizagem mais autônoma e pró-ativa, onde o aprendiz mobiliza as suas características pessoais e desenvolve estratégias assertivas para maximizar a sua aprendizagem, nas mais diversas áreas como a música, desporto ou escrita (Zimmerman, 1998). Além disso, a conscientização deste processo conduz a um maior envolvimento motivacional e à utilização de estratégias metacognitivas (Zimmerman, 2008, 2013).

A partir dos estudos sobre esta temática, Montalvo e Torres (2004) sintetizam da seguinte forma as características dos estudantes que regulam a aprendizagem: conhecem e sabem aplicar uma série de estratégias cognitivas que os ajudam a entender, transformar, organizar, elaborar e recuperar informação; sabem como planejar, controlar e dirigir os seus processos mentais, dando uso às suas metas pessoais (metacognição); apresentam um conjunto de crenças motivacionais e emocionais adaptativas (autoeficácia escolar, metas de aprendizagem, desenvolvimento de emoções positivas face às tarefas) e têm capacidade para as controlar e modificar, ajustando-as às exigências da tarefa e da situação de aprendizagem concreta; planejam e controlam o tempo e o esforço que precisam para realizar as tarefas e sabem criar e estruturar ambientes favoráveis de aprendizagem; mostram uma intenção mais forte em participar, controlar e regular as tarefas escolares, no clima e na estrutura da sala de aula; são capazes de fazer uso de uma série de estratégias volitivas orientadas para evitar distrações externas e internas, para manter a concentração, o esforço e a motivação durante a realização das tarefas. Em síntese, o que caracteriza estes alunos é que eles se sentem agentes do seu comportamento, acreditam que a aprendizagem é um processo pró-ativo, estão automotivados e usam estratégias que lhes permitem obter os resultados escolares desejados (Polydoro \& Azzi, 2009; Rosário \& Polydoro, 2012; Veiga Simão \& Frison, 2013).

De facto, a aprendizagem autorregulada pelo próprio estudante, sendo um processo multidimensional, bastante complexo e dinâmico, e pressupondo uma atividade cíclica por parte do aprendiz, resulta da interação de variáveis pessoais (conhecimentos, competências e motivações) que proporcionam ao estudante o planejamento, a organização, o controle e a avaliação dos processos adotados, dos resultados atingidos e das variáveis contextuais, que o estimulam e the dão a oportunidade de agir de uma forma intencional e estratégica. Outra variável, amplamente destacada, é a importância da percepção da autoeficácia, o uso consciente e deliberado de estratégias cognitivas e motivacionais e o empenho na conscientização dos objetivos educativos (Lopes da Silva, Veiga Simão, \& Sá, 2004).

O modelo adotado para a presente investigação refere-se a Zimmerman $(2000,2013)$ que segue em uma perspetiva sociocognitiva, envolvendo dimensões (cognitiva/ metacognitiva, comportamental, motivacional e contextual), analisando os processos psicológicos implicados nas diversas fases da autorregulação: fase prévia (forethought), fase do controle volitivo (performance/volitional control) e fase de autorreflexão (self-reflection), estando cada uma das fases interconectada de modo recíproco.

Para Zimmerman $(2000,2013)$, estas fases cumprem, assim, um ciclo de ação na autorregulação, continuamente aberto a novos desenvolvimentos, com recuos e avanços, sempre diferentes, uma vez que são enriquecidos pela experiência anterior, pelo contexto em que ocorrem e pelos resultados que se vão alcançando. A fase prévia centra-se na análise da tarefa e na influência das crenças automotivacionais. Como formas de análise da tarefa podem ser apontados: o estabelecimento de objetivos, que se refere aos resultados específicos pretendidos com a realização de uma determinada tarefa escolar e o planejamento estratégico que se reporta à seleção de estratégias ou métodos de aprendizagem necessários para a obtenção dos objetivos estabelecidos.

O planejamento estratégico e seleção de estratégias de aprendizagem requerem, por sua vez, adaptações sucessivas devido às flutuações nos componentes do contexto em que o aprendiz se situa. A fase de execução e controle volitivo é sinalizada por dois processos: o autocontrole e a automonitoração. O primeiro processo inclui as auto-instruções, as imagens mentais, a focalização da atenção, as estratégias utilizadas na realização das tarefas e a ajuda prestada aos aprendizes para se concentrarem nas tarefas e otimizarem os seus esforços. A automonitoração refere-se à atenção que o aluno dedica a aspectos específicos da sua realização, às condições que the estão subjacentes e aos efeitos produzidos. Facilmente se compreende que as estratégias de aprendizagem relacionadas com uma determinada tarefa ajudam o aluno a dividi-la nas suas partes essenciais, reorganizando-as num todo coerente.

O segundo processo na fase de controle volitivo, a automonitoração, é considerada como crucial para a autorregulação uma vez que informa o aluno acerca dos seus progressos e retrocessos face a um determinado critério de referência (e.g., classificações escolares, objetivos escolares definidos). No pressuposto de Zimmerman $(2000,2013)$ podemos distinguir a automonitoração associada à autoavaliação, à implementação de estratégias e aos esforços para as adaptar a partir dos resultados obtidos. A última fase do ciclo de autorregulação, a fase da autorreflexão, inclui dois principais processos: a autoavaliação e a autorreação. $\mathrm{O}$ primeiro refere-se à forma como o aprendiz avalia os resultados obtidos, sendo influenciado por pensamentos como as atribuições ou padrões auto-impostos. A autorreação, por 
seu turno, pode ser positiva ou negativa, diz respeito à comparação da informação automonitorada com um critério ou objetivo previamente definido.

Quando descrevemos o ciclo de autorregulação e sublinhamos a autonomia do aprendiz ao longo do processo de aprendizagem, é necessário recordar que essa autonomia depende da posse e uso adequado de processos cognitivos internos de autoinstrução e autorregulação. Do mesmo modo, Almeida (1996) lembra que é da metacognição que falamos quando o indivíduo faz uso de estratégias ditas superiores de planejamento e decisão dos componentes cognitivos de resolução de problemas e recorre a uma espécie de monitoração do seu próprio pensamento (pensar sobre o pensar). Em 1976, Flavell havia já descrito sobre o pensamento metacognitivo como aquele que se relaciona com os fatores ou as variáveis que atuam e interatuam no decurso e no produto final das atividades cognitivas, sendo eles a pessoa, a tarefa e a estratégia. Para que tal aconteça é necessário que o indivíduo se conheça como processador da informação, ou seja, que tenha consciência das suas características, que conheça as exigências da tarefa e que, de acordo com ambas, escolha a estratégia que melhor o conduz aos seus objetivos.

Segundo a perspetiva do mesmo autor (Flavell, 1976), o conhecimento e a experiência metacognitivas desenvolvem-se à medida que ocorre o desenvolvimento cognitivo, o qual vai possibilitar o aparecimento de novas operações cognitivas. Por um lado, estas operações são necessárias à aquisição de conhecimentos metacognitivos e facilitam a maturação de outras já existentes; por outro lado, o indivíduo precisa criar condições para novas experiências metacognitivas. Essencial é também que ele tome consciência dos processos que utiliza para aprender e tomar decisões apropriadas sobre que estratégias utilizar em cada tarefa e, ainda, avaliar a eficácia dessas estratégias, alterando-as quando elas não produzem os resultados esperados (Lopes da Silva \& Sá, 1993).

Mas as variáveis que intervêm no processo de aprendizagem não se esgotam nos fatores cognitivos. Faria (1995) afirma que variáveis de ordem motivacional, como por exemplo, os padrões de realização do aprendiz, as suas motivações e atribuições, as perceções pessoais e outras representações de si, da tarefa e do desempenho, interferem no processo de autorregulação da aprendizagem. No fundo, a aprendizagem e o desempenho encontram-se associados aos motivos, objetivos e intenções dos aprendizes (Ainley, 1993). Lemos (2005) faz menção ao conceito de competência percebida (associada às expectativas, autoconceito de competência e auto-eficácia) que se refere à avaliação da relação "eu-meios", isto é, à avaliação da capacidade do indivíduo para realizar as atividades relevantes para produzir um determinado acontecimento. Compreendemos, pois, que a competência percebida dos indivíduos influencia o seu desempenho e está fortemente relacionada com os resultados escolares (nível de realização em testes e notas escolares).

A investigação mostra relações significativas entre estas crenças e a utilização de estratégias cognitivas (e.g., elaboração) e metacognitivas (e.g., planejamento e monitoração) que se reflete no nível de compreensão (Printrich \& De Groot, 1990; Pintrich \& Schrauben, 1992) e se associam também a afetos, positivos ou negativos, que facilitam ou dificultam a realização da tarefa. Então, intervir ao nível da motivação implica atuar simultaneamente no domínio da competência pessoal, aumentando o recurso à utilização de estratégias de aprendizagem, e ao nível do autocontrole, favorecendo as percepções de controle pessoal através da aquisição de comportamentos que lhe permitam ensaiar o domínio sobre as tarefas escolares.

Lopes da Silva e cols. (2004) recordam que tal não será possível se os estudantes não possuírem conhecimentos sobre os atributos de estratégias específicas, sobre os mecanismos de autorregulação e não desenvolverem crenças gerais sobre a eficácia dos comportamentos orientados para um objetivo. Estes três componentes influenciam a probabilidade de utilização de estratégias de aprendizagem, potencializando, assim, o rendimento escolar (Perassinoto, Boruchovitch, \& Bzuneck, 2013).

\section{Entrevista com tarefa}

As investigações iniciais sobre esta temática encaminham para a utilização de metodologias quantitativas, as quais revelam avanços significativos. Ainda assim, permaneceram dificuldades em avaliar os processos autorregulatórios envolvidos nas tarefas desenvolvidas pelos indivíduos (Belski \& Belski, 2014; Zimmerman, 2008). De fato, em termos comparativos, as abordagens multimetodológicas qualitativas tornam possível responder a questões como "O quê?", "Como?", "Porquê?" e "Quando?", enquanto que as abordagens quantitativas respondem, normalmente, a questões como "Quanto?" e "Quantas vezes?". As primeiras perguntas sugerem, geralmente, respostas mais complexas e pormenorizadas, requerendo, quase sempre, uma argumentação por parte do respondente (Patrick \& Middleton, 2002).

Entre os instrumentos mais utilizados nas investigações de carácter qualitativo encontramos as entrevistas. A entrevista com tarefa, de acordo com Veiga Simão e Flores (2007), enquadra-se no âmbito das entrevistas semiestruturadas, que possibilita obter descrições do mundo real a partir da perspetiva do entrevistado para interpretar os significados dos fenómenos que pretendemos descrever (Kvale \& Brinkmann, 2009). Veiga Simão e Flores (2007) referem-se, por exemplo, a utilização de entrevistas com tarefa como uma metodologia que se constitui numa oportunidade de ouvir os estudantes através de descrições ricas acerca dos seus próprios processos de aprendizagem. No geral, as entrevistas semiestruturadas permitem aos investigadores selecionar, a partir do roteiro de entrevista, questões que sejam mais incisivas para o contexto e situação específicos do aprendiz, encorajando-o a refletir sobre as estratégias usadas, assim como, os seus pensamentos e sentimentos (Boekaerts \& Corno, 2005). Complementarmente, De Groot (2002) sugere que o roteiro da entrevista semiestruturada 
deve ser constituído por uma questão inicial mais geral, de resposta aberta, seguida de uma série de questões mais específicas, sem que haja necessidade de se seguir uma ordem rígida ao longo da entrevista, dependendo também das contribuições do entrevistado. Uma vez que os dados extraídos de uma entrevista dizem respeito à interação entre o entrevistado e o entrevistador, num determinado contexto temporal e cultural, o resultado deste processo é uma contínua negociação na qual o entrevistador não pode deixar de ter um papel determinante (Halldén, Haglund, \& Stömdahl, 2007), o que pode representar outra vantagem.

O entrevistado, ao fornecer novas ferramentas de comunicação ao entrevistado, pode introduzir, por exemplo, novos conceitos ou ideias. Outra das potencialidades é a possibilidade de colocar questões ao entrevistado acerca do que ele está tentando explicitar naquele momento. As entrevistas com tarefa surgem, assim, como um instrumento que permite, através de uma conversa semiestruturada com o aprendiz, acessar às dimensões cognitivas/metacognitivas e motivacionais do entrevistado. Ao conduzir o entrevistado para os temas sobre os quais se pretende recolher informação, criamos a oportunidade de entrar no seu mundo conceitual, com o objetivo de compreender como e qual o significado que constrói para os acontecimentos da sua vida quotidiana (Bogdan \& Biklen, 1994). Dado o papel relevante atribuído ao entrevistador, Cormier e Nurius (2003) recordam algumas competências básicas que devem ser asseguradas, entre elas, o estabelecimento de uma relação empática, genuína e positiva com o entrevistado, a utilização de expressões de concordância e a atenção ao comportamento não-verbal.

Esses autores recordam ainda que é essencial que o entrevistador procure oportunidades para receber feedback acerca da participação no entrevistado, uma vez que ambos estão envolvidos no processo, no decorrer entrevista. Destacamos, no entanto, que as competências do entrevistador não devem ser circunscritas à condução da entrevista. Elas estão intimamente relacionadas com o conteúdo a que se pretende chegar. De Groot (2002) sublinha que a forma como as questões são colocadas ao entrevistado adquire grande importância; ainda que este aspeto esteja fortemente relacionado com a construção do roteiro, é necessário que o entrevistador saiba adaptá-lo às circunstâncias imprevisíveis. É precisamente nas potencialidades da entrevista, enquanto instrumento, que nos centramos neste artigo.

\section{Questões de investigação e objetivos}

A partir das potencialidades da entrevista com tarefa como procedimento para identificar a complexidade e dinâmica do construto em estudo, pretendemos analisar os percursos autorregulatórios de dois alunos do Ensino Básico na realização da tarefa de resumo e contrastar as suas percepções com a análise dos percursos observados ao longo da realização da tarefa. Estes aspetos enquadram as questões que se pretende investigar: 1) De que forma a entrevista com tarefa pode auxiliar os profissionais da educação na identificação de competências da aprendizagem autorregulada? 2) Como a entrevista com tarefa se constitui como instrumento potenciador dos processos autorregulatórios dos aprendizes?

\section{Método}

Optamos por uma metodologia de caráter qualitativo, a qual privilegia a triangulação metodológica com entrevistas individuais semiestruturadas, que se constituíram como o meio privilegiado de recolha de dados, para obter a opinião dos aprendizes. Na entrevista foram consideradas: a observação indireta, as verbalizações feitas pelos entrevistados, as observações diretas, a manifestação de expressões e comportamentos dos entrevistados e, ainda, o resultado da tarefa realizada durante a entrevista. Estes artefatos, realizados em três momentos distintos, permitiram compreender os percursos autorregulatórios dos dois alunos do Ensino Básico ao realizarem a tarefa de resumo (Silva, 2010).

Os participantes foram informados de que a sua colaboração era voluntária e anônima e foi obtida a autorização prévia dos Encarregados de Educação. As três entrevistas, por participante, foram gravadas e posteriormente transcritas. No início de cada entrevista pedimos o consentimento livre e esclarecido de cada participante.

\section{Participantes}

Os participantes da pesquisa foram aprendizes com idades entre 10 e 11 anos, os quais permitiram aprofundar os processos envolvidos no ciclo de autorregulação da aprendizagem acerca da tarefa de resumo (ver Tabela 1).

Tabela 1. Caracterização dos participantes

\begin{tabular}{|c|c|c|c|c|}
\hline \multicolumn{5}{|c|}{ Participantes } \\
\hline Designação & Gênero & Idade & Ano de escolaridade & Média de classificação no início da investigação \\
\hline L & Masculino & 10 anos & $5^{\circ}$ ano do ensino básico & \multirow{2}{*}{$3($ em 5) } \\
\hline $\mathrm{R}$ & Feminino & 11 anos & $6^{\circ}$ ano do ensino básico & \\
\hline
\end{tabular}

Fonte: As autoras 
Tabela 2. Objetivos específicos dos três momentos de entrevista

\begin{tabular}{|c|c|c|}
\hline \multicolumn{3}{|l|}{ Objetivos } \\
\hline Primeiro momento & Segundo momento & Terceiro momento \\
\hline $\begin{array}{l}\text { - Conhecer as estratégias que } \\
\text { os aprendizes normalmente } \\
\text { utilizavam para realizar um } \\
\text { resumo; } \\
\text { - Compreender como o aprendiz } \\
\text { planejava, desempenhava, refletia } \\
\text { e avaliava a tarefa; } \\
\text { - Coconstruir critérios de } \\
\text { avaliação da tarefa e promover } \\
\text { a generalização desses critérios } \\
\text { (objetivo transversal a todas as } \\
\text { entrevistas). }\end{array}$ & $\begin{array}{l}\text { - Compreender de que forma os } \\
\text { aprendizes se apropriavam dos } \\
\text { critérios de avaliação da tarefa; } \\
\text { - Comparar uma nova avaliação } \\
\text { da tarefa com a avaliação } \\
\text { efetuada na primeira entrevista; } \\
\text { - Coconstruir um roteiro de } \\
\text { autoquestionamento para } \\
\text { realizar a tarefa do resumo. }\end{array}$ & $\begin{array}{l}\text { - Verificar a consolidação das } \\
\text { fases do processoautorregulatório } \\
\text { (antever e planejar, automonitorar, } \\
\text { autorrefletir e autoavaliar), } \\
\text { repetindo a utilização dos } \\
\text { artefatos aplicados desde a } \\
\text { primeira entrevista; } \\
\text { - Compreender a utilidade } \\
\text { da entrevista na otimização } \\
\text { do desempenho do aprendiz } \\
\text { relativamente à tarefa do resumo. }\end{array}$ \\
\hline
\end{tabular}

Fonte: As autoras

\section{Entrevistas}

A entrevista com realização de tarefa permite conhecer a percepção do trabalho solicitado, os planos de ações e as crenças motivacionais do aluno, assim como possibilita, após a tarefa, compreender os processos ocorridos durante a sua realização (Veiga Simão \& Flores, 2007). A tarefa selecionada (o resumo) já era utilizada pelos alunos no estudo de algumas disciplinas, nomeadamente História e Geografia de Portugal. Neste contexto, entendemos por resumo a reescrita de um texto com a manutenção de uma equivalência informativa, a realização de uma economia de meios significantes e a adaptação a uma nova situação de comunicação (Veiga Simão, 2002, Veiga Simão, Frison, \& Machado, 2015). As entrevistas aos estudantes tiveram lugar em três momentos, com o máximo de um mês de intervalo entre cada um. Para cada momento foram traçados objetivos específicos, como se pode ver na Tabela 2.

No início do processo, os Encarregados de Educação dos entrevistados preencheram uma ficha de caracterização com dados pessoais, informações relativas ao percurso escolar do aprendiz e sobre as técnicas de estudo habitualmente utilizadas por eles. Na primeira entrevista pretendíamos ter a oportunidade para que o entrevistador estabelecesse uma relação empática com o entrevistado. Pretendíamos também aprofundar o conhecimento acerca do planejamento, execução e avaliação do resumo que os aprendizes realizavam habitualmente. Este momento de entrevistas aconteceu no quinto mês do ano letivo.

No sexto mês, teve lugar a segunda entrevista que pretendia analisar de que forma os aprendizes se apropriavam dos critérios de avaliação fornecidos e o que tinham posto em prática autonomamente, desde a primeira entrevis- ta. Esta questão dependia da realização de outros resumos. Nesta entrevista foram apresentados dois novos artefatos: um roteiro de classificação da tarefa de resumo, que objetivava a classificação das ideias do texto original, e o roteiro de um autoquestionamento, coconstruído pelo entrevistado e o entrevistador, que tinha como objetivo auxiliar os aprendizes a interiorizar as fases do processo de autorregulação a partir da tarefa do resumo.

Um mês depois, foi realizada a terceira entrevista que retomou os momentos e os artefatos já conhecidos do aprendizes, encorajando-os a desempenharem a tarefa de forma completa e autônoma. Entre os artefatos a serem utilizados estavam os roteiros: do autoquestionamento, da classificação de ideias do texto original e da avaliação do resumo. Com estes instrumentos, o entrevistador preocupava-se em perceber se o aprendiz havia interiorizado os processos autorregulatórios. Para cada situação foram utilizados roteiros de entrevista semiestruturada adaptados a partir daquele construído por Veiga Simão e Flores (2007), devidamente adequados ao nível de desenvolvimento dos sujeitos envolvidos e ao contexto e objetivos pré-estabelecidos para o momento (Tabela 3).

As competências do entrevistador, quanto à condução da entrevista, foram avaliadas segundo uma grade de descrição de comportamentos adaptada de Estrela (1994). A auto e heteroavaliação, isto é, a avaliação do entrevistador por ele próprio e por um juiz externo, realizou-se a partir da leitura do protocolo da entrevista, garantindo assim o feedback e a avaliação da entrevista, com critérios baseados nos objetivos específicos de cada uma. 
Tabela 3. Sugestão de roteiro de entrevista

\begin{tabular}{|c|c|c|}
\hline Bloco & Objetivos específicos & Tópicos/questões (exemplos) \\
\hline $\begin{array}{l}\text { Legitimação da } \\
\text { entrevista. }\end{array}$ & - Motivar o entrevistado. & $\begin{array}{l}\text { Explicar a que se destina a entrevista e como vai decorrer. } \\
\text { Sublinhar a importância da colaboração do entrevistado. }\end{array}$ \\
\hline $\begin{array}{l}\text { Planejamento } \\
\text { estratégico da } \\
\text { tarefa. }\end{array}$ & $\begin{array}{l}\text { - Conhecer o interesse do aluno } \\
\text { pela tarefa; } \\
\text { - Compreender a forma como o } \\
\text { aluno percebe os objetivos da } \\
\text { tarefa; } \\
\text { - Conhecer os critérios que } \\
\text { ele utiliza para avaliar o seu } \\
\text { desempenho na tarefa; } \\
\text { - Analisar a dificuldade da tarefa. }\end{array}$ & $\begin{array}{l}\text { - O que é, para ti, um resumo? (É importante fazê-los, porquê? Onde } \\
\text { aprendeste a fazer resumos e com quem?) } \\
\text { - O que é preciso para se fazer um bom resumo? Como classificarias os } \\
\text { teus resumos? } \\
\text { - Imagina que estás a estudar agora... Lês o texto e depois? Consegues } \\
\text { fazer o resumo deste texto, já experimentaste? } \\
\text { - Achas que é uma tarefa fácil/difícil? (Porquê? Como ultrapassas essas } \\
\text { dificuldades?) } \\
\text { Vais então fazer esta tarefa... } \\
\text { Qual o teu plano? (Como a vais executar? Como vais saber se estás a fazer } \\
\text { bem ou mal? Como o vais avaliar?) } \\
\text { (na } 2^{\text {a } ~ o u ~} 3^{\text {a }} \text { entrevista) } \\
\text { - Deste a última entrevista fizeste resumos? Qual o balanço que fazes? } \\
\text { (Com que finalidade? Como ultrapassaste as dificuldades? Avaliaste os } \\
\text { resumos? Ajudou-te a...?) } \\
\text { - Utilizaste o guia de autoquestionamento? Como? Para que é que serviu? }\end{array}$ \\
\hline
\end{tabular}

\begin{tabular}{|c|c|c|}
\hline $\begin{array}{l}\text { Observação da } \\
\text { realização da } \\
\text { tarefa. }\end{array}$ & $\begin{array}{l}\text { Registar as estratégias } \\
\text { observáveis utilizadas; } \\
\text { Registar as verbalizações do } \\
\text { entrevistado (estratégias não- } \\
\text { observáveis mas verbalizadas } \\
\text { durante a execução da tarefa); } \\
\text { Registar os pedidos de ajuda e } \\
\text { as distrações; } \\
\text { Registar o comportamento } \\
\text { do aluno (persistência, } \\
\text { abandono...). }\end{array}$ & $\begin{array}{l}\text { Durante a observação da realização da tarefa anotar se faz sozinho, se } \\
\text { pede ajuda, se é sensível aos distratores, se (na } 2^{a} \text { e } 3^{a} \text { entrevista) utiliza } \\
\text { o roteiro de autoquestionamento (e.g., verificar se tem todos os materiais } \\
\text { necessários à tarefa; ler o texto, na íntegra; tomar nota de palavras } \\
\text { desconhecidas; procurar o significado das palavras desconhecidas; reler o } \\
\text { texto; selecionar as ideias principais do texto; ...), se sublinha o texto, toma } \\
\text { notas, faz um diagrama, elabora um esquema, verbaliza as dificuldades, } \\
\text { utiliza o roteiro de classificação das ideias do texto original (é muito } \\
\text { importante/ mais ou menos importante/ nada importante) .... }\end{array}$ \\
\hline $\begin{array}{l}\text { Avaliação da } \\
\text { tarefa; reflexão/ } \\
\text { reação e } \\
\text { auto-avaliação da } \\
\text { tarefa. }\end{array}$ & $\begin{array}{l}\text { - Conduzir à verbalização das } \\
\text { estratégias utilizadas; } \\
\text { - Conhecer os critérios que } \\
\text { o aluno utiliza para avaliar o } \\
\text { desempenho na tarefa; } \\
\text { - Avaliar a tarefa segundo } \\
\text { critérios pré-definidos. }\end{array}$ & $\begin{array}{l}\text { - Como procedeste para elaborar o resumo? } \\
\text { - Que dificuldades encontraste? Como as ultrapassaste? } \\
\text { - Como avalia o que fizeste (Que passos seguiste? Achas que foram os } \\
\text { passos necessários para fazer um bom resumo?) } \\
\text { Pensa nos seguintes critérios (fornecer uma operacionalização dos critérios) } \\
\text { para avaliar o resumo. Como te avalias em relação a cada um deles? Estes } \\
\text { critérios são muito diferentes dos que usavas antes? Eles te ajudam a rever } \\
\text { o que escreveste? } \\
\text { - Gostarias de mudar alguma coisa? Se repetisses, farias da mesma } \\
\text { forma?... }\end{array}$ \\
\hline
\end{tabular}

Tabela continua na próxima página. 


\begin{tabular}{lll}
\hline & & - Se tivesses que explicar a um colega como fazer um resumo, como farias? \\
& & - O que trabalhaste durante esta entrevista pode te ajudar, como? \\
$\begin{array}{l}\text { Generalização } \\
\text { do trabalho }\end{array}$ & - Coconstruir estratégias de & - Vais continuar a realizar resumos?(Se sim, da mesma forma ou de \\
desenvolvido. & planejamento, execução e & maneira diferente). Que critérios vais usar para te avaliares? \\
& avaliação da tarefa. & - As questões colocadas por mim, no início e no final da tarefa, te ajudaram? \\
& & (Pedir para que justifique, e.g., se podem ajudar; se foram úteis; se gostou). \\
& & - Que questões achas importante fazeres a ti próprio?(antes, durante e no \\
\hline \multirow{2}{*}{$\begin{array}{l}\text { Finalização da } \\
\text { entrevista. }\end{array}$} & - Promover a continuidade & Agradecer a colaboração do entrevistado. \\
\hline
\end{tabular}

Fonte: As autoras

\section{Artefatos}

Como artefatos consideramos os registos escritos pelos aprendizes que forneceram informação acrescida sobre os processos autorregulatórios implicados na tarefa: resumos realizados; roteiros de classificação das ideias do texto original (listagem de todas as ideias do texto para explicitar o grau de importância das mesmas) e roteiro de avaliação do resumo adaptado de Veiga Simão (2002) que se refere aos critérios de seleção, fidelidade, coerência e transformação do texto. Consideramos também o guia de autoquestionamento, baseado em Veiga Simão (2008), através do qual se formulavam questões que guiavam os aprendizes a: procurar informação ( $O$ que necessito saber sobre?), rever conhecimentos (O que sei sobre...?), planejar os passos necessários à resolução (O que tenho de fazer?), refletir durante o percurso (Como é que estou a fazer...?) e avaliar as estratégias adotadas ( $\mathrm{O}$ que fiz, está bem?), delineando assim um plano de ação.

\section{Técnica de análise de dados}

O processo de análise de conteúdo das entrevistas foi organizado segundo as questões de investigação, numa lógica de microanálise. Segundo esta abordagem, examinamos os pensamentos específicos dos estudantes e as suas ações enquanto realizam as suas tarefas de estudo. A microanálise difere de outros procedimentos retrospectivos porque avalia os processos específicos mentais e de comportamento dos estudantes, tal como eles ocorrem e se modificam. Foi, assim, possível destacar os processos e as estratégias dos aprendizes envolvidos nas fases de autorregulação da aprendizagem (antevisão e planejamento estratégico, execução e autorreflexão) e a evolução do perfil do indivíduo (Cleary, 2011; Zimmerman, 2008).

\section{Resultados e Discussão}

Os resultados das entrevistas com os dois aprendizes foram tratados separadamente, não havendo o intuito de os comparar. Como o registro do processo de análise de cada entrevista efetuaram-se as respetivas sínteses inferenciais e a avaliação do produto segundo os critérios de avaliação do resumo, nas entrevistas em que o aprendiz realizava a tarefa.

\section{Síntese Inferencial e Avaliação do Produto - caso R}

No geral, os objetivos apontados para a primeira entrevista foram atingidos, foram recolhidas informações acerca das estratégias gerais de estudo do aprendiz e, especificamente, das estratégias de planificação do resumo. As verbalizações do entrevistado permitiram-nos inferir acerca dos seus processos psicológicos associados às fases do processo de autorregulação. Assim, foi possível atingir o objetivo que leva o aprendiz a realizar habitualmente a tarefa ("para ver se decoro") e a utilidade que atribui às estratégias que utiliza ("dão resultado!"). Destacamos também algumas crenças relacionadas com a estrutura do resumo: retira informações de diferentes fontes exteriores a ele (a professora e o livro) e utiliza estratégias de cópia-eliminação. De qualquer forma, a sua percepção de autoeficácia pareceu ser ajustada já que verificamos uma atitude coerente a partir da comparação com o plano elaborado.

Relativamente às estratégias observáveis de execução da tarefa, elas passaram por sublinhar, fazer setas e escrever a lápis, entre outras. Destacamos também processos no controle volitivo, como a automonitoração, quando o aprendiz persistia na tarefa, apesar de haver ruídos exteriores. O aprendiz mostrou ser capaz de refletir e de se autoavaliar, não só pelo produto da tarefa, mas também em comparação com terceiros. Quando pensou sobre o seu de- 
sempenho, o aluno verbalizou algumas dificuldades de compreensão, assim como, a necessidade de utilizar estratégias de revisão para melhorar o seu resumo. Atribuiu ainda uma valência negativa a duas questões: a disciplina selecionada e a tarefa de leitura em voz alta, ambas associadas a uma reduzida percepção de autoeficácia. Em consequência destes factos, conferiu utilidade e valor à entrevista que, referiu, "me vai ajudar bastante".

Relativamente à avaliação do resumo elaborado pelo aprendiz segundo os critérios de avaliação fornecidos, verificamos que o entrevistado compreendeu o texto mas não conseguiu distinguir as ideias principais, tendo mobilizado também ideias acessórias. O resumo não estava completamente fiel ao texto original, já que o sentido das frases nem sempre era claro, para além de não haver coerência no tempo verbal utilizado. As estratégias de cópia-eliminação resultaram, como se previa, em frases "telegráficas". As transformações efetuadas foram raras, já que algumas frases do resumo eram iguais às do texto original e, quando o estudante optou por condensar mais do que uma ideia na mesma frase, o sentido original ficou alterado.

$\mathrm{Na}$ segunda entrevista foi igualmente possível compreender as estratégias que o aprendiz utilizou para elaborar a tarefa e a percepção de sua utilidade, atribuindo-Ihe uma valência positiva ("Porque foi umas horas de estudo"). A sua percepção de autoeficácia continuava ajustada ao seu desempenho, mesmo quando se tratava de uma nova tarefa (classificação das ideias do texto original).

Verificamos alterações, num sentido evolutivo, relativamente ao objetivo que movia o estudante ("para conseguir perceber melhor a matéria") e na atribuição das normas de ação que passaram a ser internas ("Fazia na minha livre vontade. Porque percebia quando precisava..."). A classificação das ideias do texto original permitiu um espaço de discussão entre o aprendiz e o entrevistador que conduziu à justificação das escolhas do aluno. A coconstrução do roteiro de autoquestionamento deu oportunidade ao aprendiz de reestruturar o seu plano de ação para a preparação, execução e autorreflexão da tarefa, sendo, inclusivamente, capaz de antecipar a sua reação afetiva aos distratores (“...e eu enervo-me...").

Ao nível das estratégias para elaboração da tarefa, o aprendiz fez uso do roteiro de autoquestionamento que o ajudou no cumprimento dos passos necessários e reforçou a sua percepção de autoeficácia, realizando o trabalho autonomamente. Verificamos também a noção de adequação dos objetivos da tarefa e a tentativa de valorização do esforço ("posso mostrar à minha professora o que fiz"). Relativamente ao momento de controle volitivo, as verbalizações do aprendiz permitiram avaliar, não só, a utilização de estratégias de automonitoração (estar calmo, fazer silêncio, concentrar-se), mas também de uma autorregulação emocional e de atenção aos distratores.

Relativamente à autorreflexão, observamos uma evolução na adoção de estratégias de revisão, na autoanálise da tarefa e do plano realizado, que reforçaram também a percepção de autoeficácia. Na análise global das entrevis- tas, o aprendiz foi capaz de uma autorreflexão e autoconscientização sobre a evolução da sua produção (consultar alguns sinónimos no dicionário e ler o resumo em voz alta), bem como de perceber a utilidade e o valor das entrevistas para o seu desempenho. Todavia, a valência negativa atribuída à disciplina de História não foi desmistificada ao longo do processo. Quanto à avaliação do produto da última entrevista, a utilização da classificação das ideias do texto original pareceu ter surtido efeito uma vez que o resumo que o aprendiz apresentou é consideravelmente mais curto em extensão, quando comparado com o primeiro resumo elaborado na primeira entrevista. As ideias principais estavam presentes, havendo menor utilização de ideias acessórias. As frases eram claras, apesar de ainda não construir parágrafos aglutinadores de várias ideias, mantendo a utilização de estratégias de cópia-eliminação sem fazer utilização de sinônimos.

\section{Síntese Inferencial e Avaliação do Produto - caso L}

A primeira entrevista efetuada permitiu conhecer as razões que levam o aprendiz a optar pelo resumo como estratégia de estudo para algumas disciplinas (para perceber melhor a matéria e sistematizá-la) e compreender como o faz. As normas de ação eram externas ao aprendiz, havendo referência à professora que "também tira as coisas mais importantes e começa a resumir tudo." O aprendiz verbalizou que atribuía utilidade e agrado à tarefa, formulando expectativas em relação aos resultados e referindo algumas estratégias de compreensão ("leio, leio até conseguir perceber"). Na fase de controle volitivo, destacou-se a capacidade de monitoração da tarefa, interrompendo-a para procurar esclarecer dúvidas de vocabulário. Ainda é preciso referir algumas estratégias observáveis como o fato de não sublinhar nem tomar notas, mas de optar por copiar para uma folha branca as ideias que consideravam mais importantes.

Verificamos que, no momento da autorreflexão, a percepção de autoeficácia do aprendiz revelou-se um pouco desajustada face às suas expectativas iniciais já que considerou a tarefa "um bocadinho" difícil. Foi capaz de comparar o resultado com o plano inicial e de adotar algumas estratégias de compreensão ("Reli, tentei perceber melhor o texto...”). Quando questionado, o aprendiz revelou agrado pela estrutura da entrevista. No geral, o produto do resumo efetuado pelo aprendiz segundo os critérios de avaliação adotados para esta investigação, foram respeitados. Ainda assim, para além de constarem as ideias principais do texto original, estavam ainda presentes algumas ideias acessórias. Denotou-se pouca utilização da paráfrase e de combinações entre parágrafos na elaboração do resumo, já que muitas frases eram as do texto original.

$\mathrm{Na}$ segunda entrevista o aluno verbalizou as estratégias que utilizavam para elaborar a tarefa, reforçando a sua percepção de autoeficácia sobre as mesmas. Desta vez, o objetivo que conduzia o entrevistado na elaboração da tarefa foi mais explícito, assim como, as suas crenças 
acerca da estrutura do resumo ("Como o resumo é escrever o texto mais pequeno tendo o mesmo conteúdo..."). Apesar de ter mostrado concordância neste aspecto, o aprendiz não fez explicitamente referência à necessidade de adequar os objetivos conforme a finalidade da tarefa.

A classificação das ideias do texto original e a sua explicação demonstrou uma boa competência de argumentação; o aprendiz esclareceu as suas escolhas e utilizou sinônimos. Revelou, também, competência para repensar a sua classificação ("agora, pensando melhor...") e, por vezes, alterá-la consoante a contra-argumentação. A coconstrução do guia de autoquestionamento traduziu-se numa oportunidade para o estudante repensar a sua linha de ação, construindo, em vários passos, as fases de antevisão e planejamento estratégico, controle volitivo e autorreflexão da tarefa. Relativamente à segunda fase, sublinhou-se a referência à automonitoração da tarefa ("procurar ajuda quando não percebemos") e a atenção aos distratores ("quando já não há visitas em casa, que o cão já foi dormir, que já não temos fome podemos ir fazer o resumo concentrados").

$\mathrm{Na}$ autorreflexão, destacamos a coerência na adoção de estratégias de revisão, através da comparação com o plano elaborado inicialmente, e a utilização autônoma de estratégias de compreensão ("escrito de forma diferente mas com o mesmo conteúdo, se calhar conseguia explicar melhor"). A entrevista continuou a ser percebida como útil e, até, mais agradável do que a primeira.

A terceira entrevista permitiu consolidar o trabalho efetuado ao longo do processo, encorajando o aprendiz a apropriar-se dos artefatos construídos. Os passos que constavam no roteiro de autoquestionamento haviam sido interiorizados: "fiz sozinho", referiu o entrevistado, reforçando assim a sua percepção de autoeficácia. Ainda sobre o mesmo instrumento, o aprendiz verbalizou a necessidade de adequar os objetivos da tarefa, com o contexto.

Realçamos a competência de argumentação do entrevistado aquando da classificação das ideias do texto original como, de resto, já se tinha verificado na segunda entrevista, sendo capaz de repensar a sua classificação e, eventualmente, reformulá-la. Nos processos implicados no controle volitivo, destacamos a capacidade de automonitoração com esclarecimento de dúvidas ("posso acrescentar um comentário?") e a atenção aos distratores. Ao nível da autorreflexão da tarefa, sublinhamos a referência aos objetivos das estratégias ("compreender a matéria e ficar na nossa cabeça") e a percepção de utilidade da tarefa, continuando a comparar o plano elaborado inicialmente com o resultado obtido.

Em relação ao balanço das entrevistas, o aluno destacou a percepção de utilidade do processo e fez uma avaliação emocional do trabalho desenvolvido ("sinto-me mais rico"). A avaliação do produto demonstrou que o aprendiz pareceu ter mobilizado para o resumo os critérios introduzidos. O texto final era, de fato, mais curto, condensando informação e fazendo uso da paráfrase. O produto continha todas as ideias principais e algumas ideias acessórias (classificadas pelo próprio como "mais ou menos importantes"), mas era fiel ao texto original.

\section{Conclusões}

Os resultados desta investigação possibilitaram compreender como os aprendizes desenvolvem processos e estratégias característicos do ciclo de autorregulação da aprendizagem durante as fases de prévia, execução/controle volitivo e autorreflexão da tarefa. Assim, verificamos a elaboração de um plano da ação a partir do objetivo da tarefa, questão que é coincidente com Veiga Simão (2002) quando afirma que as estratégias de aprendizagem aplicadas pelos aprendizes autorregulados são conscientes, intencionais e relacionadas com um objetivo. Os participantes fizeram também uso da automonitoração da tarefa referindo a necessidade de focalizar a atenção (Zimmerman, 2000) quando procuravam um lugar e um ambiente adequados para estudar ou quando pediam ajuda para ultrapassar determinadas dificuldades. Na sistematização das características dos aprendizes autorregulados levada a cabo por Montalvo e Torres (2004), os autores consideraram que os estudantes conhecem e são capazes de aplicar uma série de estratégias, tanto de elaboração, como de organização, facto também aqui evidente, por exemplo, da necessidade de aplicar estratégias de metacompreensão ("reli o texto para tentar perceber melhor"). Esta questão parece ser coincidente com Teixeira e Alliprandini (2013) que concluíram que a intervenção em estratégias de aprendizagem fornece subsídios para que o aluno se torne mais ativo na aprendizagem no que diz respeito, não apenas às estratégias cognitivas, mas também às estratégias metacognitivas. Destacamos, ainda, e de forma especial, a percepção de autoeficácia dos alunos para realizar as tarefas. Lopes da Silva e Sá (1993) referem que os problemas motivacionais dos alunos com baixo rendimento provêm da sua história escolar, povoada de repetidos insucessos que podem ter ocorrido desde o início da sua escolaridade. Contrariamente, os participantes desta investigação eram aprendizes que, ao longo do seu percurso, tinham conseguido um nível de realização médio e médio-alto, o que poderá explicar a sua elevada percepção de autoeficácia relativamente às tarefas propostas.

Em relação à evolução dos perfis dos aprendizes, encontramos indicadores, no terceiro momento de entrevistas, de que eles já eram capazes de adequar os objetivos da tarefa conforme as situações. Lopes da Silva e cols. (2004) mencionam precisamente que os objetivos de realização, não sendo apenas objetivos globais, servem de orientação geral para a tarefa. Ao longo das entrevistas, os participantes deram também indícios de se tornarem capazes de interiorizar algumas normas de ação. Ou seja, quando, num primeiro momento, as normas de ação da tarefa (elaborar um resumo) eram transpostas apenas daquilo que a professora havia dito na aula ou do que o livro indicava, no final do processo os aprendizes mostravam já ter consciência dessas normas, conseguindo auscultar a necessidade de como e quando planejar e executar a tarefa.

Outro indicador da evolução dos aprendizes ao longo do processo diz respeito à utilização de estratégias de revisão. No que se refere à elaboração do primeiro resumo, ne- 
nhum dos aprendizes relia o resumo feito depois de concluir. Mas, já no segundo momento, quando da coconstrução do roteiro de autoquestionamento, ambos referiam a necessidade de ler o resumo e, eventualmente, melhorá-lo.

No geral, o estudo contribuiu com dados que permitem responder às questões de investigação colocadas, já que a entrevista com tarefa parece ser um instrumento adequado para identificar processos implicados nas fases de autorregulação da aprendizagem. Sendo um estudo exploratório com potencialidades de ser alargado, este instrumento torna-se uma ferramenta útil no trabalho dos profissionais da educação. Por outro lado, foi igualmente possível, através da utilização da entrevista com tarefa, auxiliar os aprendizes a conhecerem-se melhor e a potenciar as suas competências autorregulatórias. Destacamos, de fato, a importância das interações entre o aprendiz e o entrevistador, tendo este último contribuído para a melhoria do projeto do entrevistado, por exemplo na coconstrução de artefatos, cuja relevância havia sido sublinhada por Halldén e cols. (2007).

Há necessidade de referir que a opção metodológica apresenta, só por si, algumas limitações. Relativamente ao grau de consolidação da utilização dos artefatos por parte dos aprendizes, se o entrevistado repetisse a tarefa do resumo após a classificação das ideias do texto original, a partir da segunda entrevista, a apropriação dos critérios de elaboração e de avaliação da tarefa talvez fosse mais eficaz. As dificuldades esperadas ao identificar as estratégias e os processos autorregulatórios implicados nas tarefas desenvolvidas pelos aprendizes haviam já sido antecipadas por Zimmerman (2008). Todavia, assumindo as potencialidades da entrevista com tarefa como instrumento de identificação dos processos autorregulatórios, pretendemos contribuir para a sua difusão entre os profissionais da educação, ajudando a contrariar a tendência de efetuar avaliações demasiado diretas (e.g., escolha múltipla), privilegiando, ao invés, o processo de construção (Sasaki, Oliveira, Barreto \& Rocha, 2014).

Outras propostas dizem respeito à gravação da entrevista em vídeo que possibilitaria a validade na auto e heteroavaliação do entrevistador e o uso da estimulação da recordação pelo participante; a aplicação da entrevista com outras tarefas, para além do resumo; a intervenção continuada com os aprendizes e devolução dos resultados aos professores; a consolidação dos processos autorregulatórios e o aperfeiçoamento de técnicas, promovendo um projeto de formação investigação-ação (Cadório \& Veiga Simão, 2010) entre diferentes profissionais da educação.

\section{Referências}

Ainley, M. D. (1993). Styles of engagement with learning: multidimensional assessment of their relationship with strategy use and school achievement. Journal of Educational Psychology, 85, 395-405.

Almeida, L. (1996). Cognição e aprendizagem: como a sua aproximação conceptual pode favorecer o desempenho cognitivo e a realização escolar. Psicologia: teoria, investigação e prática, $1,17-32$

Belski, R. \& Belski, I. (2014). Cultivating student skills in self-regulated learning through evaluation of task complexity. Teaching in Higher Education, 19 (5), 459-469. doi:10.1080/13562517.2014.880685.

Boekaerts, M. \& Corno, L. (2005). Self-regulation in the classroom: a perspective on assessment and intervention. Applied Psychology: an International Review, 54 (2), 199-231.

Bogdan, R. \& Biklen, S. (1994). Investigação Qualitativa em educação. Uma introdução à teoria e aos métodos. Porto: Porto Editora.

Cadório, L. \& Veiga Simão, A. M. (2010). A investigação-acção na formação de professores: um caso de auto-regulação da aprendizagem. Em P. Alves, P. \& A. Flores (org), Trabalho docente: desmistificar conceitos, fundamentar práticas (pp. 101-127). Colecção Educação e Formação. Mangualde: Edições pedago.

Cormier, S. \& Nurius, P. (2003). Interviewing and change strategies for helpers: Fundamental skills and cognitive behaviour interventions (5th ed.). Pacific Grove: Brooks Cole.

De Groot, E. (2002). Learning through interviewing: students and teachers talk about learning and schooling. Educational Psychologist, 37 (1), 41-52.

Cleary, T. (2011). Emergence of Self-regulated Learning Microanalysis. In B., Zimmerman, \& D., Schunk, (Eds.), Handbook of SelfRegulation of Learning and Performance (pp. 87-101). New York, NY: Routledge.

Estrela, A. (1994). Teoria e Prática de Observação de classes. Uma estratégia de formação de professores. Lisboa: Instituto Nacional de Investigação Científica.

Faria, L.M.S. (1995). Desenvolvimento diferencial das concepções pessoais de inteligência durante a adolescência. Porto: Universidade do Porto, FPCE (Tese de Doutoramento).

Flavell, J.H. (1976). Metacognitive aspects of problem solving. Em L. Resnick (Ed.), The nature of intelligence (pp. 231-235) Hillsdale, N. J.: Lawrence Erlbaum Associates, Publishers.

Halldén, O., Haglund, L., \& Stömdahl, H. (2007). Conceptions and contexts: on the interpretation of interview and observational data. Educational Psychologist, 42 (1), 25-40.

Kvale, S. \&. Brinkmann, S. (2009). Interviews: Learning the Craft of Qualitative Researche Interviewing. California: SAGE Publications.

Lemos, M. (2005). Motivação e Aprendizagem. In G. Lobato Miranda \& S. Bahia (Org.) Psicologia da Educação: Temas de desenvolvimento, aprendizagem e ensino. Lisboa: Relógio D’Água. 
Lopes da Silva, A. \& Sá, I. (1993). Saber estudar e estudar para saber. Porto: Porto Editora.

Lopes da Silva, A., Veiga Simão, A.M., \& Sá, I. (2004). A autorregulação da aprendizagem: estudos teóricos e empíricos. InterMeio, 19 (10), 58-74.

Montalvo, F. \& Torres, M. (2004). El aprendizaje autorregulado: presente y futuro de la investigación. Revista Electrónica de Investigación Psicoeducativa, 2 (1), 1-34.

Patrick, H. \& Middleton, M.J. (2002). Turning the kaleidoscope: what we see when self-regulated learning is viewed with a qualitative lens. Educational Psychologist, 37 (1), 27-39.

Perassinoto, M., Boruchovitch, E. \& Bzuneck, J. (2013). Estratégias de aprendizagem e motivação para aprender de alunos do Ensino Fundamental. Avaliação Psicológica (online), 12 (3), 351-359. Recuperado em agosto de 2014 de http://pepsic.bvsalud.org/ scielo.php?script=sci_arttext\&pid=S1677-04712013000300010

Pintrich, P. R. \& De Groot, E. (1990). Motivational and self-regulated learning components of classroom academic performance. Journal of Educational Psychology, 82, 33-40.

Pintrich, P. R. \& Schrauben, B. (1992). Student's motivational beliefs and their cognitive engagement in classroom tasks. Em D. Schunk \& J. Meece (Eds.), Student perceptions in the classroom: Causes and consequences (pp. 149-183). Hillsdale, NJ: Erlbaum.

Polydoro, S. \& Azzi, R. (2009). Autorregulação da aprendizagem na perspectiva da teoria sociocognitiva: introduzindo modelos de investigação e intervenção. Psicologia da Educação (online), 29, 75-94. Recuperado em set. 2014 de http://pepsic.bvsalud.org/ scielo.php?script=sci_arttext\&pid=S1414-69752009000200005

Rosário, P. \& Polydoro, S. (2012). Capitanear o aprender: promoção da autorregulação da aprendizagem no contexto escolar. São Paulo: Casa do Psicólogo (série Teoria Social Cognitiva em contexto educativo).

Sasaki, K., Oliveira, L., Barreto, M., \& Rocha, N. (2014). Percepções de estudantes do ensino fundamental sobre sua avaliação de aprendizagem. Psicologia Escolar e Educacional, 18 (1), 77-86.

Silva, J. (2010). Entrevista mediante tarefa com aprendentes do $2^{\circ}$ ciclo: uma aplicação da Autorregulação da Aprendizagem. Tese de mestrado apresentada na Faculdade de Psicologia da Universidade de Lisboa.
Teixeira, A. \& Alliprandini, P. (2013). Intervenção no uso de estratégias de aprendizagem diante de dificuldades de aprendizagem. Psicologia Escolar e Educacional, 17 (2), 279-288.

Veiga Simão, A.M. (2002). A aprendizagem estratégica. Uma aposta na autorregulação. $N^{\circ}$ 2, Desenvolvimento Curricular. Lisboa: Ministério da Educação.

Veiga Simão, A.M. (2008). Reforçar o valor regulador, formativo e formador da avaliação das aprendizagens. Em M. Alves \& E. Machado (Orgs.), Avaliação com sentido(s): Contributos e Questionamentos (pp. 125-151). Santo Tirso: De Facto Editores.

Veiga Simão, A.M. \& Flores, A. (2007). Using interviews to enhance learning in teacher educations. Proceeding of the 52nd ICET World Assembly ICET and 6th Annual Border Pedagogy Conference "Borders, Boundaries, Barriers and Frontiers: Promoting Quality in Teacher Educations". San Diego, Califórnia, USA.

Veiga Simão, A. M., Frison, L., \& Machado, F. (2015). Escrita de resumo e estratégias de autorregulação da aprendizagem. Cadernos de Pesquisa, 45 (155), 30-55. Fundação Carlos Chagas.

Veiga Simão, A.M. \& Frison, L. (2013). Autorregulação da aprendizagem: abordagens teóricas e desafios para as práticas em contextos educativos. Cadernos de Educação, 45, 2-20.

Zimmerman, B. J. (1998). Academic Studying and Development of Personal Skill: a Self-Regulatory Perspective. Educational Psychologist, 33 (2/3), 73-86.

Zimmerman, B. J. (2000). Attaining self-regulation: a social cognitive perspective. Em M. Boekaerts, P. Pintrich \& M. Zeidner (Eds.), Handbook of Self-Regulation. New York: Academic Press. 13-39.

Zimmerman, B. (2008). Investigating self-regulation and motivation: historical background, methodological developments, and future prospects. American Educational Research Journal, 45, (1), 166 $-18$.

Zimmerman, B.J. (2013). From Cognitive Modeling to Self-Regulation: A Social Cognitive Career Path. Educational Psychologist, 48 (3), 135-147. 


\section{Sobre as autoras}

Janete Silva Moreira (janetesilva@campus.ul.pt)

Psicóloga Educacional. Doutoranda em Psicologia, na especialidade de Psicologia da Educação na Faculdade de Psicologia da Universidade de Lisboa.

Ana Margarida Veiga Simão (amsimao@psicologia.ulisboa.pt)

Professora Associada com Agregação na Faculdade de Psicologia da Universidade de Lisboa. Coordenadora da secção de Psicologia da Educação e Orientação na mesma Faculdade. 